\title{
TEACHING AND LEARNING CYCLE TECHNIQUE IMPLICATION TO BOOST THE THIRD SEMESTER STUDENTS' ABILITY IN GRAMMAR OF D3 ENGLISH PROGRAM OF UNIVERSITAS BENGKULU
}

\author{
Kasmaini, SS.,MPd \\ Universitas Bengkulu, Indonesia \\ kasmainiunib@gmail.com
}

\begin{abstract}
The aim of this research was to investigate the ability of the third semester students of D3 study program of universitas Bengkulu in using appropriate grammar by implementing the teaching and learning cycle technique. This is a classroom action research. It was done in genre writing class. There were 23 students. Three instruments were applied in this research such as observation, fieldnote and test. From the observation result, it could be seen that there was the students' activeness and the increasing ability of the students in using grammar for certain text type. The fieldnote results also showed that the amount of the students asking in the class increased, the ability to make appropriate title for certain text type, the use of appropriate vocabulary and grammar increased too. From the last intrument, test, also found that there was significant increase of students' average score from the first to the third cycle. The score was 64,71 and 82. At last, it can be concluded that the technique of teaching and learning is successful to increase students' ability in using appropriate grammar for a certain text type.
\end{abstract}

Key words: grammar, teaching and learning cycle technique, text type

\section{INTRODUCTION}

The success of learning can be gained from two things: the process and the outcome. From the learning outcome, it also can be seen through some clues such as the final score of semester. For example, the ability of students on the writing subject in the last semester could depict the ability of students in the next semester

In line with the students' writing ability, the researcher observed the quality of writing written by students of the third semester of D3 English Language Program of the Faculty of Teachers Training and Education University of Bengkulu who took the subject of Genre Writing which is still very low. She analyzed the text written by the students contain a lot of errors. The errors are about placing inappropriate sentence or grammar structures such as narrative-sstyle essays that are generally written inpast tense with present tense, or the errors of using appropriate diction by using first form of verb instead of second form of verb. Beside of that, the errors also happen in the choice of word with the correct sense. 
From the text written by the students in Genre writing subject, it is also seen that their essay is less coherent. One paragraph not only develops one main idea but more than one ideas. This is also due to the fact that they are not used to using the right transition signal. Based on the results of question and answer, it is known they are having difficulies in determining the topic to be written. Those difficulties make them less interested in writing, particularly writing in English.

Due to difficulties in writing, this is also experienced by students in countries who use English as both as the second language and as the first language let alone the students of English D3 program FKIP UNIB where English is still a foreign language of course the rules and rhetoric of English language different from their language, Indonesian. Richard and Renandya (2002) say that writing is the most difficult skill for the second language learners to master. This means, that writing is indeed the most difficult skill to be mastered for the second language learner including D3 English students FKIP UNIB as a foreign language learner. Furthermore, Yan (2005) say that in EFL teachers and students encounter certain problems in the process of teaching and learning writing. So the difficulties in writing are also experienced by the teacher in the process of learning to write.

In regards of learning writing in Indonesia, Emilia (2005) says that the teaching of writing English in Indonesia needs to be improved for two reasons: lack of time and practice or practice in writing coherent text in various genres (text type).

Based on the problems above, whom currently experienced by semester two students, the researcher keens to immediately conduct classroom action research on the third semester students of English D3 program in Genre writing course. In this subject, the students are expected to be able to write various types of text by way and the placement of sentence structure (grammar) and the right choice of words and the composition of coherent ideas (according to the syllabus of the genre writing course of English D3 Study Program FKIP UNIB)

Seeing the description of the syllabus and problems experienced by the students as mentioned above, the researcher felt that the teaching and learning cycle technique is highly appropriate because this approach, besides focusing on writing or writing on text type, Teaching and Learning Cycle technique also has five stages in teaching writing such as building the context, modeling and deconstructing the text, the joint construction of the text, the independent construction of the text and linking related text. These five stages make learning to write not a one-off writing task but rather an ongoing process with scaffolding from 
the teacher (lecturer), which over time, the intensity will decrease in accordance with the student's progress.

With the teaching and learning cycle and scaffolding above, the researcher believes the students will be helpful in determining the title to be written (building the context), how to write paragraph with certain text type (modeling and deconstructing the text), and how to use appropriate grammar or correct sentence structure as well as word choice for certain text types (Joint construction of the text and independent construction of the text). At the time they write, the researcher or the lecturer will also help them if the students are having trouble (scaffolding) and at the end of their writing practice, they will be given time to correct their writing by comparing what they have written with other paragraphs of the same kind or not to see how far they can write correctly (Linking related text).

This teaching and learning cycle technique allows teaching of writing less intimidating for students. They will be happy to write and not feeling that writing is boring and writing the same idea over and over again. The repetition will bring to perfection in writing. Practice makes perfect. Besides, the students are not removed from the beginning. They will be guided according to the level of difficulty they face. As they begin to understand what will be written with the right structure, the researcher will reduce the aid. Therefore, researchers through this research will see how far this technique can improve students' grammar ability in writing various types of paragraphs and the extent to which this approach can be a non-boring teaching for students.

\section{Teaching Writing}

The teaching of writing is not the same as reading or other skills. Writing has several characters such as provisions, clarity, idea organization and standard language. According to Ur (2000) the teaching of writing is to teach the students how to express ideas, and convey a message to the reader. This means teaching writing stresses to students that what we write should be acceptable to what we think to the reader. In other words, the writing must be careful and consecutive with the correct arrangement.

Writing is one of four skills every student has to have in learning a language and it is also the same as an English D3 student. In writing many things to note such as the idea to be written, the correct way of writing and the rules. Particularly in writing paragraph in English students must understand two cultures namely the culture of writing their languages and the culture of writing in English where these two rhetorics of writing are different. Indonesian does 
not have the change of word form as it is in English and the change of tensesalong with the story of a thing. So writing not only requires knowledge of the rules of writing but also knowledge of culture into which language we write.

Writing has several stages in accordance with the level of courses that are in progress. In English D3 course, there are three stages: paragraph writing, essay writing, and academic writing. Especially in the course of paragraph writing, the class to be held is research, students are expected to be able to write one or more paragraphs in various types of text.

There are several types of texts such as narrative text, exposition, argumentation, persuasion and description. These five types of paragraphs have their own character. For examples descriptive essays have social functions describing people, things and places, generic structures describing the phenomena that described and the description show the part, the quality of the description and the characteristics of the description . commonly, tense use is present tense. Tense is in use is usually present tense. Certainly, these characters do not apply for other types of articles such as narratives that generally use tense in Past form.

\section{The Concept of Genre Approach}

The term genre is not a new thing anymore. This term is often used in everyday conversations such as Friday sermons, presidential speeches, singing contests and daily conversations between mothers. All of these examples represent different genres because each genre has different audiences, different delivery methods, differentcontent,and different goals. In general, genre means the type or style (Paltridge,2001). In other words, the genre is a particular type of text with a particular pattern or mode of delivery and a specific purpose and audience or reader.

Consider genre as an approach, Paltridge (2001) said approach refers to the theory of language and language learning that underlies the particular approach or methodology. So the genre approach can mean a language teaching approach that discusses the types of text.

Hyland (2004) said genre approach is one of the most important and influential concept in language education. This means that the genre approach is helpful in language teaching because it provides a framework that enables one to interpret a communicative situation. This provides knowledge to students or language learners to be able to communicate well in this case in writing form. Meaning that in this genre approach the student must connect what he wrote to the context where and what he wrote. This context that makes the writing can 
dialogue with the reader appropriately. To realize those all, in the genre approach there are two techniques namely teaching and learning cycle and scaffolding.

\section{Teaching and Learning Techniques Cycle (Learning cycle technique)}

Teaching Techniques and Learning cycles in genre approach is a classroom activity cycle consisting of 5 steps. This activity can be the form of techniques and procedures in creating an atmosphere in the classroom. This cycle was designed by Feez and Joyce (1998) aiming to provide teachers or lecturers and students toward their own capability in writing a text. The five steps are (1) building context, student activities at this stage such as: introduced in the social context of an authentic text model to be studied, studying the context characters of the culture that will be written and social purpose of the text. (2) Modeling and deconstruction of text, activities at this stage are learning sentence patterns and characteristics of the exemplified text and comparing text models with others. (3)Join construction of the text, the student activity in this stage is like a student camparing the construction of the text of the model. (4) the construction of independent text, at this stage the student begins to work independently writing a text and, (5) linking to the related text, the student compares the text that they write with existing texts from various types such as narrative, expository etc. to make sure they acknowledge the type text they wrote.

This means the five stages enable students to correct and understand the text in detail. In performing the stages the students were also given a gradual teaching which called scaffolding in genre approach.

\section{Findings of Relevant Researches}

There were several studies that have been done connected with the application of the genre approach in teaching writing. The study was conducted by Bhatia in Candlin and mercer (2001). He researched business letters about promotions and job applications. The result is that the two letters appear with different contexts because they have different contexts.

Emilia (2005) has also undertaken research on the effectiveness of using genre approaches in teaching students writing English language learning at state universities in Java. The results showed that there are some weaknesses but the teaching programs are successful. Students in these universities appreciate more in class discussions, the democracy atmosphere 
in bringing together different lecturers' ideas and roles that enable them to be more active in class.

From both studies can be seen that the genre approach is very useful in teaching writing. Therefore, the researcher believes this research will also have a positive impact for teaching writing for the second semester students of English D3 program in the paragraph writing course.

\section{METHOD}

This research is a classroom action research. This type of research aims to improve where the practice of learning is done. Mills (2003) states that classroom action research is; "action researchis a systematic inquiry conducted by teacher researcher to gather information about the ways that their particular school operates, how they teach, how well the students learn. The information is gathered with the goals of gaining insight, developing reflective practice,effecting positive changes in the school environment and on educational practices in general and improving students' outcomes.

This research is a classroom action research designed for two cycles. Each cycle consists of four meetings. Each cycle consists of planning, action, observation and reflection. The research procedure in each cycle is as follows:

Cycle 1

1. Planning (Plan)

a. Designing activities to be carried out during teaching and learning process with genre approach

b. Providing text models to be used in teaching and learning process (description, exposition, narrative and argumentation)

c. Dividing students into groups

d. Students write individually

2. Action (Action)

a. The lecturer explains the context of the text models and their characteristics

b. The lecturer divides the example of the text to be the model.

c. Discuss the structure of sentences, sentence patterns and the context of the text model.

d. Discuss the text components above in class and group discussions.

e. After looking at the readiness of the students, they are asked to find their own titles and write individually 
f. The lecturer collects the students' writing for corrections by the team, the chairman and the research members.

\section{Observation}

a. Other lecturers, research members, observe the learning process done by the researcher and vice versa while the researcher members teach the other lecturers to observe.

b. The observing lectures observe the checklist on the observation sheet.

\section{Reflection}

The team discusses the results of direct observation and observation checklists as well as students' writing work to see the extent of the weaknesses in this one cycle and plan for corrective actions for the next cycle, cycle two.

\section{Cycle II and Cycle III}

The second and third cycles were based on changes in planning and action in accordance with the problems in the previous cycle. The study was conducted on D3 student of English semester 2 FKIP UNIB. The time of the research is from March to September 2017in the paragraph writing subject. Meanwhile, the subjects in this research are students of the 3rd semester of the academic year 2016-2017.

The numbers of the students in this study are 23 people. The main instrument of this research is the researcher as the subject of writing paragraphs. Other instruments are checklist sheets, and tests are performed at the end of each cycle. These tools are for getting the right answers in written form.Observation is a technique used by observing carefully and focusing on matters relating to the advancement of appropriate grammar or tense when they write in class.Associated with the test, Cresswell (2005) said the test is a series of questions or exercises used to measure skills, knowledge, intelligence, abilities or talents possessed by individuals or groups. The test to be performed at the end of each cycle is a test of paragraph writing according to the type requested. Assessment will use Heaton's theory. The validity and reliability of this test use expert validity ie researchers and collaborators (2 researchers).

The main instrument of this research is the researcher himself as a lecturer. Other instruments used are observation, field-note and test. Checklist is done to see the activity of students in the lecture. While, the observationused to see the application of teaching and learning cycle techniques. To make observations and checklists, researcher asks for help to colleagues to make observations. This is done because researcher can't observe carefully when the learning process is in progress 
The test is used to see the improvement of capability in each cycle. The test is done three times which is the test at the end of each cycle. The results of this test will give an idea of improving students' writing skills from cycle one to end of cycle three. This test is only as supporting data. The most important thing is how the numbers can be achieved.The result of the writing test is analyzed by using Heaten method.

The improvement of students' writing skills is reflected from the results of the writing tests given at each end of the cycle. The indicators of success in this research are as follows: (1) Students are able to recognize the types of text (type of text) that is spoof, report anddescriptive.(2). Students are able to develop the text by using the structure of sentence (grammar) is good and correct.(3). Students are able to place the right choice of words.(4). Students are able to organize the text coherently.

\section{DISCUSSION}

\section{Cycle I.}

\section{Planning of Action.}

Planning of action which is appropriate with the arranged research scenario before doing action is introducing teaching and learning cycle technique to the students and deciding kind of text that will be used in cycle I. The kind of text is spoof text.

\section{Implementation of Action.}

The implementation of action in the cycle I which is appropriate with the steps from teaching and learning cycle technique that consist of five steps such as what is existed in the design in chapter 3 . The five steps are (1) building the context, the students activities in this step is: introduced to the social context of authentic spoof text that will be learned, learning the characteristics of cultural context from the text that will be written and social goals from the text, learning the situational context from the text that is based on the goals and students' needs, (2) Modeling and deconstructing the text, the activity in this step is learning the sentence pattern and the linguistics character from the spoof text, which is the dominant of using tense, (3) Joint construction of the text, the students activity in this step is the students discuss the construction of spoof text. (4) Independent construction of the text, here, the students begin to work individually to write a spoof text. The students write by their own language style. They are not allowed to download from the internet and (5) linking to related text, here, the students 
compare the text they write with the existing text from the various field, such as narrative, expositive, etc. to convince that they have mastered kind of spoof text that have been written.

\section{Observation.}

In this step, the colleague (observer) and the researcher observe the course by implementing teaching and learning cycle technique. In this step the observer notice the students' attitude, behavior and activeness in learning. In the first meeting, the students is looked enthusiastic enough in following the lesson, because they are given the information about teaching and learning cycle technique which is preceded by the explanation of grammar functional by Michael Halliday (1985) as the basic theory of this technique. Here, the researcher also explains the advantages that may be gotten after implementing the technique.

The topic talked is also interested for the students. The topic about spoof text challenges them to think of creating the way that is happy ending or funny (punch line).It is also noticed in this observation, that there are many students ask about grammar from the spoof text. Part of them was not understood yet about the use of past tense in a whole on the context. Usually, they only use in the cut sentence without including it in a situational context and cultural context.

\section{Reflection.}

The result of reflection from this cycle I gives a description to the researcher and the observer about some weaknesses that must be fixed in the next cycle. The weaknesses that were seen from the observer were: (1)Students' activeness is still little. There were only some of them who asked.(2 ). When writing individually, most of the students were still doubt about the use of past tense.

\section{Field note Result.}

There were some checklists seen from the observation in the class. They were:(1)The totals of students asking about grammar were still a little.(2)The totals of students who can decide a title appropriate with the characteristic of spoof text were not yet so many.(3)The totals of students who use proper vocabularies were still less.(4)The totals of students who use proper grammar were still a little. From the instrument, it was obtained that only part of students can decide a title which is appropriate with the spoof text and use past tense. While, there were only some people who ask. There was also a little who can use appropriate vocabularies. 
Table 1. Test Result of Cycle 1

\begin{tabular}{|c|c|c|}
\hline No. & Name & Score \\
\hline 1 & DEP & 72 \\
\hline 2 & DS & 70 \\
\hline 3 & UTD & 70 \\
\hline 4 & VF & 62 \\
\hline 5 & PS & 73 \\
\hline 6 & DIH & 60 \\
\hline 7 & MKS & 62 \\
\hline 8 & ERA & 72 \\
\hline 9 & $\mathrm{MFN}$ & 55 \\
\hline 10 & FSP & 59 \\
\hline 11 & YF & 69 \\
\hline 12 & GTP & 62 \\
\hline 13 & JFPR & 60 \\
\hline 14 & AAS & 64 \\
\hline 15 & MA & 60 \\
\hline 16 & $\mathrm{D}$ & 62 \\
\hline 17 & $\mathrm{DP}$ & 62 \\
\hline 18 & ES & 60 \\
\hline 19 & AIB & 65 \\
\hline 20 & $\mathrm{NC}$ & 75 \\
\hline
\end{tabular}


21 MWN

22 RRR

23 MAK
60

65

62

From the table above, the average score of writing the spoof text of third semester students in D3 English Education Study Program were 64. From the result, it is estimated that those students still have many obstacles in writing spoof text.

\section{Cycle II. Planning of Action.}

The implementation of action in this cycle is adapted from the observation result of cycle 1 .

\section{Implementation of Action.}

The implementation of action in the cycle II is appropriate with the deficiencies that must be fixed and the steps from teaching and learning cycle technique consisted of five steps. The five steps were (1) building the context, the students' activity in this step, such as: introduced to the social context of authentic report text that will be learned, learning the characteristics of cultural context from the text that will be written and social goals of the text, learning situational context of the text based on the students' needs and goals, in this step, the researcher was more stressing on the title appropriateness with the kind of text and cultural and situational context of the text. (2). Modeling and deconstructing the text, the activity in this step was learning the sentence pattern and linguistics character of report text, that is the dominant of using simple present tense, before students write, in this step, the researcher gives knowledge about simple present tense and when they use the tense. There are three functions of this tense, they were to explain daily events, to explain the habit and to explain the common fact. After that, the students were told to create some sentences of simple present tense and some exercises about this tense. (3). Joint construction of the text, the students' activity in this step was discussing the construction of report text, the students with the help (scaffolding) from the researcher were analyzing generic structure and linguistic features of report text. They were asked to compare the report text with the spoof text that has been made in the cycle I. Here, they can understand differences between two texts, so they can understand in more detail about the report text. (4). Independent construction of the text, here, the students were starting to work individually by writing a report text. The students write with their own language style. They were not allowed to download from the internet. They were allowed to search supported 
data or idea from some resources including online sources. They were asked to be able to arrange an idea from the sources with their own flow of thought. And (5) linking to related text, here, the students compare the kind of text they write with the existing text from various field, that is spoof text which has been learned in cycle I.

\section{Observation.}

In this step, the colleague (observer) and the researcher were observing the course by implementing teaching and learning cycle technique. In this step, the observer notices students' attitude, behavior, and activeness in learning. In this cycle, the students were looked enthusiastic in following the course, because they have been given information about teaching and learning technique cycle in the previous cycle. In this observation, it is also noticed that many students asked about grammar from the report text. Part of them have been able to use simple present tense, but the others, sometimes still mixed with other tenses, such as present continuous tense and present perfect tense.

\section{Reflection.}

The result of reflection from the cycle II gives description to the researcher and the observer about some weaknesses that must be fixed in the next cycle. The weaknesses that were noticed from the observation were: (1)Students' activeness was almost thorough, but some people still choose to be silent.(2)When writing individually, most of the students were able to do it, but they still need more exercises about simple present tense.

\section{Field note Result.}

There were some checklists seen through class observation. They were:(1)There have been many students asked about grammar.(2)The total of students who were able to decide a title appropriate with the characteristic of report text has improved.(3).Almost the whole students use proper grammar.(4)Most of the students have used proper grammar. From this instrument, it was obtained that most of the students were able to decide a title appropriate with the report text and use "simple present tense". Most of them have been able to use proper vocabularies.

\section{Table 2. Test Result of Cycle 2}

\begin{tabular}{|c|c|c|}
\hline No & Name & Score \\
\hline 1 & DEP & 80 \\
\hline 2 & DS & 75 \\
\hline
\end{tabular}


Allughah, Language Journal

$\begin{array}{lll}3 & \text { UTD } & 80 \\ 4 & \text { VF } & 69 \\ 5 & \text { PS } & 70 \\ 6 & \text { DIH } & 65 \\ 7 & \text { MKS } & 77 \\ 8 & \text { ERA } & 80\end{array}$

9 MFN 65

$\begin{array}{lll}10 & \text { FSP } & 70\end{array}$

$\begin{array}{lll}11 & \text { YF } & 67\end{array}$

$\begin{array}{lll}12 & \text { GTP } & 69\end{array}$

$\begin{array}{lll}13 & \text { JFPR } & 69\end{array}$

$\begin{array}{lll}14 & \text { AAS } & 72\end{array}$

$\begin{array}{lll}15 & \text { MA } & 67\end{array}$

$\begin{array}{lll}16 & \mathrm{D} & 65\end{array}$

$\begin{array}{lll}17 & \mathrm{DP} & 67\end{array}$

$\begin{array}{lll}18 & \text { ES } & 68\end{array}$

$\begin{array}{lll}19 & \text { AIB } & 67\end{array}$

$\begin{array}{lll}20 & \mathrm{NC} & 80\end{array}$

21 MWN 73

$\begin{array}{lll}22 & \text { RRR } & 65\end{array}$

23 MAK 67 
From the table above, it was obtained the average score of writing report text was 71 . It can be causes by students' familiarity in using teaching and learning cycle technique. They were able to understand the tense used through analyzing generic structure and linguistic feature from the text.

\section{Cycle III.}

\section{Planning of Action.}

Planning of action in the cycle is corresponding to the weaknesses which still exist in cycle 2 . The steps done is still referring to the steps from teaching and learning cycle technique, but there were any addition on particular points, such as giving more exercises about tense that will be used and emphasizing generic structure from text that will be written.

\section{Implementation of Action.}

Implementation of action in this cycle III is corresponding to the steps of teaching and learning cycle technique which consist of five steps. Those steps were (1) building the context, the students' activity in this step was like: introduced to the social context from authentic spoof text which will be learned, learning the characteristic of cultural context from the text that will be written and social goals of the text, learning situational context from the text based on students' needs and goals, in this cycle III, students have been familiar with the way how to find out social and cultural context from the text that will be written, which is a descriptive text. (2). Modeling and deconstructing the text, the activity in this step was learning sentence pattern and linguistics character of descriptive text, which is the dominant of using simple present tense, (3). Joint construction of the text, here, the students begin to work individually by writing a descriptive text. The students write with their own language style. They are not allowed to download from the internet and (5) linking to related text, here, students compare the kind of text that they write with the existing text, such as spoof text in cycle I and report text in cycle II.

\section{Observation.}

In this step, the colleague (observer) and the researcher observe the course by implementing teaching and learning cycle technique. In this step, the observer noticed students' 
attitude, behavior, and activeness in learning. In the meeting in cycle III, the students is looked enthusiastic in following the course, because they were given information about teaching and learning cycle technique and they were common in using this technique. The topic about descriptive text makes them easy in writing because what will they write was existed around them and can be seen directly. In this observation, it was also noticed that almost all students have understood about grammar from the descriptive text.

\section{Reflection.}

(1)The result of reflection from this cycle III gives a description to the researcher and the observer that most of the weaknesses seen from observation in cycle II have been resolved. The description was below:(1)The students' activeness has been equally.(2)When writing individually, almost all of students were able to write a descriptive text with proper grammar and proper choose of words which are appropriate with the social and cultural context from the text.

\section{Fieldnote Result.}

There were some checklists seen through observation in the classroom. They were:(1)The whole students have asked about grammar. (2)The total of students who were able to decide a title appropriate with the characteristic of descriptive text has been equally.(3)Almost all students have used proper vocabularies.(4)Most of the students have used proper grammar, only 1 or 2 people who were less proper.

From this instrument, it was obtained that there have been almost all students were able to decide a title appropriate with the descriptive text and using simple present tense.

\section{Table 3 Test Result of Cycle 3}

\begin{tabular}{|c|c|c|}
\hline No & Name & Score \\
\hline 1 & DEP & 78 \\
\hline 2 & DS & 75 \\
\hline 3 & UTD & 78 \\
\hline 4 & VF & 75 \\
\hline
\end{tabular}


$6 \mathrm{DIH}$

$7 \quad \mathrm{MKS}$

80

8 ERA

82

$9 \mathrm{MFN}$

76

$10 \quad$ FSP

82

11 YF

80

12 GTP

78

13 JFPR

76

14 AAS

78

15 MA

85

$16 \mathrm{D}$

85

17 DP

75

18 ES

77

19 AIB

75

$20 \mathrm{NC}$

85

21 MWN

76

22 RRR

82

23 MAK

77

From the table of cycle III above, it was known that the average score of writing descriptive text of third semester students of D3 English Education Study Program was 82.From three instruments above, observation, field note and test, there were some things shown the success in improving grammar ability of third semester students of D3 English 
Education Study Program Faculty of Teacher Training and Education University of Bengkulu by using teaching and learning cycle technique. From the observation result in cycle 1, it was known that many students were not active yet. Only some of them were asking. When writing individually, most of the students still doubt about the use of past tense.

This was caused by D3 English Students were not familiar yet in using this grammar in a context. If creating a sentence using past tense, they were seen understand well. This can be solved by the existing of teaching and learning cycle technique where by five steps existed, students were invited to use grammar (past tense) gradually to the context. For instances, by introducing an example of spoof text. After they were given a model, then it is analyzed in detail anything that build the text. Started from the way to arrange its idea until realize it, that is through past tense. Here, students were not asked to write directly, buy gradually.

As what has been stated by Hyland (2004) that genre approach is one of the most important and influential concept in language education. It means that genre approach is very helping in language teaching, because this approach gives framework that makes someone can interpret communicative situation. It means by genre approach realized in the classroom by teaching and learning cycle technique, it may make students were able to use grammar which appropriate with the context. From the result of observation in cycle II, it was obtained a description that there was any improvement of students' activeness in learning. Most of them were asking, so the grammar that will be used to write a report text, which is past tense can be more understood. They do this because by existing of modeling or habituation in previous cycle. It means that teaching and learning cycle technique allows teaching of writing becomes not scary for the students. They will feel pleased to write and do not feel that writing is bored and writing same ideas repeatedly.

The repetition will bring to perfectness in writing. Practice makes perfect. From observation in cycle III, it was seen much significant improvement, whether from students' activeness in pre-writing or while writing. They were very enthusiastic in writing, because they understand what will be written. They have had a guidance, which is generic structure and significant lexico - grammatical features from descriptive text that they are going to write. The use of tense that is appropriate with the text can be seen from the test result which is done in every end of the cycle.Along with the situation above, Sudrajat (2011), referring from L de Fink thought in his writing entitled Active Learning, active learner consist of two main components, they are main element, which is experience element covering doing activity and observing activity, and dialog covering dialog with themselves and dialog with others. In other 
words, students will not active in learning if they do not experience it yet. In this case, it is the tecnique of teaching and learning cycle.

From three cycles done, there are three field note result. Those three field note results show quality improvement from each item seen. The improvement was occurred, such as the total of students who asked about grammar from the less, most of them, until almost all of them were asking. This was occurred because teaching and learning cycle technique can create pleasure situation in learning. It is in line with Feez and Joyce (1998): teaching and learning cycle technique aims to give steps for teacher or lecturer and students toward they were able to write a text individually. Then, it is about the total of students who were able to decide a title appropriate with the characteristic. This situation was rising from still not many, most of them (in cycle II) and finally almost equally in cycle III. While the next point from this checklist is about the total of students who use proper grammar, started from still less, many, and finally equally except one or two people who were not able yet.

The third instrument from this classroom action research is test. The test was done in every end of the cycle to see the progress occurred after implementing teaching and learning cycle technique. From cycle I, cycle II, and cycle III, it was seen that there are any improvement of writing score, in this case was the score of using grammar which is appropriate with the context from the texts written by D3 English Students. The texts written were used as a media to see students' mastery in using tense or grammar which are appropriate with the social and cultural context.

Table 4.Comparation of Average Test Result of Cycle 1, 2, and 3

$\begin{array}{cc}\text { Cycle } & \text { Average Score } \\ \text { Cycle I } & 64 \\ \text { Cycle II } & 71 \\ \text { Cycle III } & 82\end{array}$




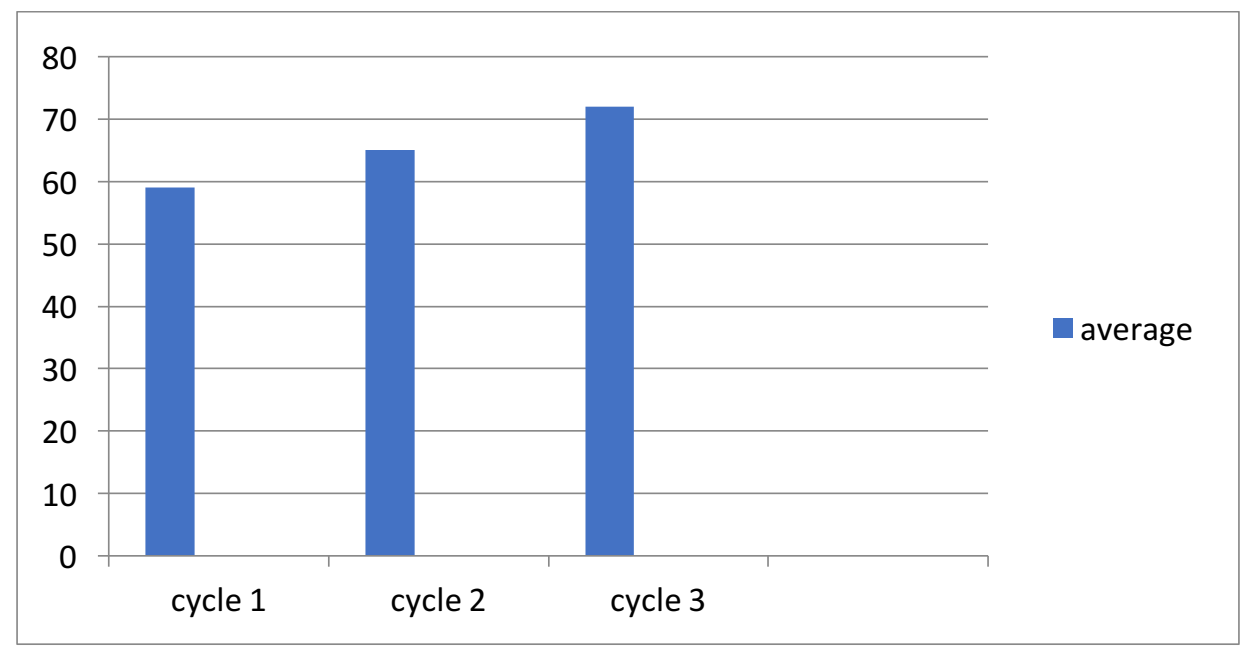

Chart I. The Average Score of Cycle I, II, and III

From the table and chart above, it was seen in cycle I, the students' average score is 64 . If seen from this number, it is proved that D3 English Students' mastery toward grammar is still low. Students should be able to reach higher mastery level. From this test result, the researcher does some changes of learning scenario. They were sharpening information about grammar. Increase exercises and question and answer about tense used. The information or explanation was covering function and vocabulary change. If it is about past tense, it will occur some changes of verb form or to be that is used. Here, it is needed second form of verb. This activity is done repeatedly to see students' mastery level. As has been said by Feez and Joyce (1985) that repetition can bring perfectness.

Test result of cycle II, the average students were improving sharp enough from 64 to 71. The improvement was 7 points. The positive thing occurred because there were any scenario changes about grammar at the beginning of cycle II. The researcher realizes that there were any students who have ability below the others. For that, the researcher conducts a discussion that discuss about generic structure and grammar which are used in the report text. Here, the grammar used is different from the spoof text, but the way to understand is still in the steps existed in teaching and learning cycle technique. Emilia (2005) said that students in universities are more appreciating discussion in the classroom, atmosphere of the freedom of expressing idea and different lecturer role that allows them to be more participated actively in the class.

From the average score in cycle III, it was seen clearly the changes of grammar mastery that was significant. The average score was becoming 82 . Individually, there were still some 
D3 English Students who got score below 75. This is shown that teaching and learning cycle technique is successful in improving grammar mastery of D3 English Students of FKIP UNIB.

\section{CONCLUSION}

From the implementation of teaching and learning cycle technique in genre writing subject at third semester students of D3 English Study Program Faculty of Teacher Training and Education, it can improve grammar ability of the students. This is seen from the improvement of average test result which is done every end of cycle. The improvement also occurs by students activeness involved in the learning. The result of this research also can be used for subject with other skills, such as reading. The implementation of this strategy if used for the same skill is wished that having same characteristic with this research subject for the maximum result.

\section{REFERENCES}

Candlin, N and Mercer, Neil.2004. English Language Teaching in its Social Context. London. The Open University

Emilia, Emi.2005. " The Effectiveness of Genre Based Approach In Academic Teaching Writing at a State University in West Java", (online), (http://curry, Edschool.Sydney. edu/epltt/genrebasedapproach.Html, Retrieved on June $3^{\text {rd }} 2006$ at $8.0 o$ am)

Hyland.2004. Genre and Second Language Teaching. Ann Arbor: The University of Michigan Press

Johnson, Andrew P. 2005. A Short Guide to Action Research. Boston: Pearson Education, Inc.

Kemmis and Robin.1988. The Action Research Planner. Sydney: Deakin University Press

Paltridge. 2001. Genre and the Language Learning Classroom. Ann Arbor: The University of Michigan Press

Richards and Renandya. 2002. Methodology in Language Teaching. Cambridge: Cambridge University Press

Ur,Penny.2000. A Course of Language Teaching:Practice and Theory.Cambridge.Cambridge University Press

Yan, Guo.2006."Genre and and the Language Learning Classroom". English Teaching Forum.Vol 43. No 3 